\title{
Fatal and non-fatal drowning in rivers
}

\author{
Jonathon Webber ${ }^{1,2}$ (D) Andrew C. Schmidt ${ }^{3,4}$. Justin R. Sempsrott ${ }^{5}$. \\ David Szpilman $^{6}$ - Ana Catarina Queiroga ${ }^{7} \cdot$ Tessa Clemens $^{8} \cdot$ Natalie Hood $^{9}$
}

Accepted: 9 May 2017 /Published online: 5 June 2017

(C) Springer Science+Business Media New York 2017

In response to the letter from Byard [1] describing two drowning incidents in the Murrumbidgee River in Wagga Wagga, and the author's own experience with being rescued himself, we commend those involved for executing a safe rescue. Drowning while attempting rescue accounts for $2 \%$ of all drowning-related deaths in Australia [2]. In many cases it is the person in distress that survives, and the would-be rescuer who dies [3]. We agree that a better understanding of the omnipresent dangers associated with rivers is needed, as these locations feature prominently in the Australian and New Zealand drowning statistics $[4,5]$. Our concern, and reason for corresponding, is the continued use of the outdated

Authors Jonathon Webber, Andrew C. Schmidt, Justin R. Sempsrott, David Szpilman, Ana Catarina Queiroga, and Tessa Clemens are members of the International Drowning Researchers' Alliance, http:// idra.world/.

Jonathon Webber

jweb018@aucklanduni.ac.nz

Andrew C. Schmidt

andrew.schmidt@jax.ufl.edu

Justin R. Sempsrott

justin@lifeguardswithoutborders.org

David Szpilman

david@szpilman.com

Ana Catarina Queiroga

acqueiroga@me.com

Tessa Clemens

tessa_clemens@edu.yorku.ca

Natalie Hood

nataliehood67@hotmail.com

1 Department of Anaesthesiology, The University of Auckland, Private Bag 92019, Victoria Street West, Auckland 1142, New Zealand terminology "near drowning". In 2002, the World Congress on Drowning developed the following uniform definition for drowning: "The process of experiencing respiratory impairment due to submersion or immersion in liquid" [6]. With this definition also came the recommendation to discontinue the use of modifiers such as "near", "secondary", "wet/dry", and "active/passive". Whereas "drowning" was often used to describe a fatal event, based on this uniform definition, which has been adopted by the World Health Organization and Centers for Disease Control and Prevention, the primary definition does not include outcome. From this definition, terms like "fatal", "non-fatal", or "drowning with morbidity" can be

2 Surf Life Saving New Zealand, PO Box 39129, Lower Hutt 5045, Wellington, New Zealand

3 Department of Emergency Medicine, University of Florida College of Medicine-Jacksonville, 655 W 8th St, Jacksonville, FL 32209, USA

4 Lifeguards Without Borders, 1311A Canal Dr, Carolina Beach, NC 28428, USA

5 Lifeguards Without Borders, PO Box 737, Kuna, ID 83634, USA

6 Sociedade Brasileira de Salvamento Aquático, Av das Américas 3555, Bloco 2, Sala 302, Barra da Tijuca, Rio de Janeiro, RJ 22631-004, Brazil

7 EPI-Unit, Institute of Public Health, University of Porto, Rua das Taipas, 135, 4050-600 Porto, Portugal

8 School of Kinesiology and Health Science, York University, 4700 Keele St, Toronto, ON M3J 1P3, Canada

9 Surf Life Saving Australia, Locked Bag 1010, Rosebery, NSW 2018, Australia 
used to better describe the event. The use of outdated terminology is unfortunately not a rarity in peerreviewed literature, as a systematic review we recently performed and are seeking publication of, found that $32 \%$ of drowning-related articles over the past six years included non-uniform terminology. We see this as an opportunity for editors to improve the published use of uniform drowning terminology. It is also our hope that improved data collection and reporting lead to improved practice and patient outcomes.

\section{Compliance with ethical standards}

Declarations All authors have no funding sources to report. All authors have made a substantial contribution to this work. All authors have no conflicts of interest or competing financial interests.

\section{References}

1. Byard RW. Drowning and near drownings in rivers. Forensic Sci Med Pathol. 2017; doi:10.1007/s12024-017-9858-5.

2. Royal Life Saving Society Australia. Royal Life Saving national drowning report 2016. Sydney: Royal Life Saving Society Australia; 2016. pp. 10. http://www.royallifesaving.com.au/facts-and-figures/ research-and-reports/drowning-reports. Accessed 5 May 2017.

3. Franklin RC, Pearn JH. Drowning for love: the aquatic victiminstead-of-rescuer syndrome: drowning fatalities involving those attempting to rescue a child. J Paediatr Child Health. 2011;47:44-7.

4. Peden AE, Franklin RC, Leggat PA. The hidden tragedy of rivers: a decade of unintentional fatal drowning in Australia. PLoS One. 2016;11(8):e0160709.

5. Water Safety New Zealand. New Zealand Drowning prevention report 2016. Wellington: Water Safety New Zealand; 2017. http://www. drownbase.org.nz/annual-statistics/. Accessed 5 May 2017.

6. Van Beeck EF, Branche CM, Szpilman D, et al. A new definition of drowning: towards documentation and prevention of a global public health problem. Bull World Health Organization. 2005;83:853-6. 